\title{
Mathematical modeling of convection drying process of wood taking into account the boundary of phase transitions
}

\author{
Sokolovskyy Ya. I. ${ }^{1}$, Boretska I. B. ${ }^{2}$, Gayvas B. I. ${ }^{3}$, Kroshnyy I. M. ${ }^{2}$, Nechepurenko A. V. ${ }^{2}$ \\ ${ }^{1}$ Lviv Polytechnic National University, \\ 12 S. Bandera Str., 79013, Lviv, Ukraine \\ ${ }^{2}$ Ukrainian National Forestry University, \\ 103 Gen. Chuprynky Str., 79057, Lviv, Ukraine \\ ${ }^{3}$ Ya. S. Pidstryhach Institute for Applied Problems of Mechanics and Mathematics, \\ 3B Naukova Str., 79060, Lviv, Ukraine
}

(Received 29 March 2021; Revised 15 October 2021; Accepted 9 November 2021)

\begin{abstract}
The article deals with constructing and implementing mathematical models of nonisothermal moisture transfer during drying of anisotropic capillary-porous materials, in particular wood, taking into account the movement of the evaporation zone for non-steady drying schedules, as well as to the development of effective analytical and numerical methods for their implementation. An analytical-numerical method for the determination of non-isothermal moisture transfer under non-steady schedules of the drying process has been developed, taking into account the dynamics of the phase transition boundary change. Calculation relationships are established for determining the phase transition temperature taking into account transport gradients and time for which the relative saturation reaches the boundaries of the phase transition.
\end{abstract}

Keywords: boundary of phase transition, non-isothermal moisture transfer, mathematical model.

2010 MSC: 80A19, 80A22

DOI: $10.23939 / \mathrm{mmc} 2021.04 .830$

\section{Introduction}

The intensification of the technology of drying colloidal capillary-porous materials leads to further development of mathematical modeling of heat-and-mass transfer processes, phase transformations taking into account the deepening of the moisture evaporation zone, which would adequately describe the laws of moisture removing in the materials being dried. The processes of drying moist materials, in particular of natural origin, are characterized by significant energy consumption. This is due to the high specific heat of evaporation of moisture in large quantities. The drying process of capillary-porous materials is accompanied by a deepening of the zone of moisture evaporation inside the material. The presence of a moving boundary of phase transformations at the interface between phases with different thermophysical and mechanical characteristics considerably complicates the mathematical models of heat-and-mass transfer processes during the drying of capillaryporous materials. The simulation of heat-and-mass transfer with phase transitions in the drying process is reduced to solving Stefan problems which are the most complicated even for minor changes in the density of the material in the evaporation zone. Therefore, there is an objective need to construct mathematical models of non-isothermal moisture transfer and study the influence of thermodiffusion on mass transfer in the drying of capillary-porous materials, taking into account the motion of the evaporation zone for nonstationary drying schedules, as well as to develop effective analytical and numerical methods for their implementation. The vast majority of drying processes of capillary-porous materials, in particular wood, is accompanied by a deepening of the zone of moisture evaporation inside the material [1-4]. The boundary of the phase transition itself depends on time, and its identification is carried out in the process of finding a solution, which determines the nonlinearity of the mathematical models under 
study. From a mathematical point of view, the boundary value problems of heat conduction in the region with a moving boundary (the so-called generalized boundary value problems) are fundamentally different from the classical problems of heat conduction. The application of classical methods of separation of variable, integral Fourier transforms is problematic here. This is due to the fact that it is not possible to match the solution of the heat conduction equation with the motion of the boundary in the heat transfer region. The use of classical methods was successful for the problems when the law of the boundary motion is predetermined [5]. Analytical studies were carried out for limited cases of the well-known law of boundary motion, for example, linear or parabolic. For this purpose, the methods of thermal potentials, contour integration, power series, "instantaneous" Greenberg eigenfunctions were used [6]. Obtaining analytical solutions of a generalized boundary-value problem in a region with a moving phase transition boundary by arbitrary law was reduced to integro-differential equations [7]. Sufficiently effective method for solving the problems of heating and kinetics of drying moist materials is the method of differential series [8]. For numerical implementations of mathematical models of heat and mass transfer with phase transitions, two main approaches are used. The first approach uses methods with the phase boundary detection at each time span [9]. For the second approach, end-to-end calculation methods are used, in particular, using the generalized formulation of the classical Stefan problem $[10,11]$. To solve multidimensional problems of heat-and-mass transfer with a phase transition, the use of numerical methods with explicit separation of the phase boundary in many cases is accompanied by algorithmic and computational difficulties [12]. In this case, the methods of end-to-end calculation have become widespread. To do this, a generalized formulation of the classical Stefan problem is used. Based on the methods of solving quasilinear problems of heat conduction, the corresponding numerical methods for solving the Stefan problem are constructed [13]. Such problems also use the enthalpy formulation of Stefan problem and economic difference schemes [14]. In recent years, the control volume approach [15] for solving these problems has become the most widespread. Using this method (integral-interpolation method), a discrete formulation of Stefan's problem was obtained. It is reduced, depending on the dimension of the problem, to the problem of finding the solution to a system of linear algebraic equations with a three-, five-, or seven-diagonal matrix. The solution of such systems is obtained using the sweep method (for one-dimensional case) and the method of alternating directions (for two- and three-dimensional cases). The finite-difference approximations for the implementation of mathematical models, which provides accounting for the eridarity and selforganization of the material, were used in the works $[23,26]$. Non-integer integro-differentiation was used in $[21,22]$ to model systems characterized by "memory" effects, structural heterogeneity, spatial non-locality, deterministic chaos, and self-organization. Therefore, the paper is aimed at studying mathematical models of non-isothermal moisture transfer and establishing patterns of thermodiffusion influence on mass transfer during drying of anisotropic capillary-porous materials, taking into account the movement of the evaporation zone for non-stationary drying schedules, as well as developing effective analytical and numerical methods for implementing the models. Such mathematical models and methods of analysis will make it possible to develop new and improve existing technological processes for hydroscopic treatment of organic materials, in particular wood.

\section{Mathematical modeling of heat-and-mass transfer during drying of capillary-porous bodies, taking into account the phase transition boundary under unsteady conditions}

A mathematical model of heat-and-mass transfer in the drying process, taking into account the phase transition boundary for a capillary-porous plate with a thickness of $2 L(-L \leqslant z \leqslant L)$ is constructed, $z$ is coordinate. The plate is attributed to the Cartesian reference system. During the drying process, the plate is in contact with a gaseous environment, which is a mixture of dry air and vapor. It is assumed that the thermal conditions on the surfaces of the plate are the same and the drying process is symmetric with respect to the middle surface. During the drying process, a dried zone and a zone saturated with moisture appear in the plate. The contact boundary $L_{m}$ of these zones extends into

Mathematical Modeling and Computing, Vol. 8, No. 4, pp. 830-841 (2021) 
the depth of the porous plate. The mathematical model of the process of heat-and-mass transfer in a plate during drying, taking into account changes of the phase transition boundary $L_{m}$ over time is constructed as follows. The heat transfer equation in the region $0 \leqslant L_{m} \leqslant L$ takes the form:

$$
\left(\Pi\left(c_{\nu} \rho_{\nu}+c_{\alpha} \rho_{\alpha}\right)+(1-\Pi) c_{s} \rho_{s}\right) \frac{\partial T(z, \tau)}{\partial \tau}=\frac{\partial}{\partial z}\left(\lambda_{c} \frac{\partial T(z, \tau)}{\partial z}\right)+F
$$

where $\lambda_{c}$ is coefficient of heat conduction, $c_{\nu}, c_{\alpha}, c_{s}$ are specific heat capacity of vapor, air, wood carcass, are density values of the same moist plate components, $F$ is internal source; $\Pi$ is material porosity $T=T(z, \tau)$ is temperature, $\tau$ is time.

The effect of the porous structure of the wood plate is taken into account by introducing effective binary interaction coefficients into the Stefan-Maxwell equation. The Stefan-Maxwell equation system is complemented by the Darcy filter equation with effective viscosity $\mu_{g}$ and permeability $K_{g}$ characteristics and the ideal gas equation. Then we write down the Stefan-Maxwell equation with respect to functions $\rho_{\alpha}, \rho_{\nu}$ :

$$
\begin{gathered}
\rho_{\alpha} \frac{K_{g}}{\mu_{g}} \nabla\left(\frac{\rho_{\alpha}}{M_{\alpha}}+\frac{\rho_{\nu}}{M_{\nu}}\right) R T+D^{\prime} \nabla \rho_{\alpha}=0, \\
\nabla\left(\rho_{\nu} \frac{K_{g}}{\mu_{g}} \nabla\left(\frac{\rho_{\alpha}}{M_{\alpha}}+\frac{\rho_{\nu}}{M_{\nu}}\right) R T+D^{\prime} \nabla \rho_{\nu}\right)=0,
\end{gathered}
$$

where $K_{g}$ is the permeability coefficient depending on the radius of the capillaries, $\mu_{g}$ is the dynamic viscosity coefficient of gas.

The recorded nonlinear system of differential equations (2), (3) is valid in the drying region which is limited by the boundary surface and the surface that is determined by the coordinate $L_{m}$. For further studies, it is assumed that on a moving surface $z=L_{m}$ the vapor density is equal to the density of the saturated vapor, i.e. $\rho_{\nu}=\rho_{\nu n}$. The conditions on the boundary surfaces $z=L$ are written as follows:

$$
\rho_{\nu} \frac{K}{\mu_{g}} \frac{\partial P}{\partial z}+D^{\prime} \frac{\partial \rho_{\nu}}{\partial z}=-j, \quad \rho_{\alpha}=\rho_{\alpha 0}
$$

where $j=\tilde{\beta}\left(\rho_{\nu}-\rho_{\nu 0}\right) ; \tilde{\beta}$ is the mass transfer coefficient. As the mass transfer problem is further solved in a quasi-stationary formulation, and $T_{m}$ is the unknown phase transition temperature which is dependent on the saturation pressure, we shall assume $T_{m}=f\left(P_{n}\right)$, where $P_{n}$ is the saturated vapor pressure.

The equation of energy balance at the moving boundary of phase transitions $z=L_{m}$ is written in the form:

$$
-\left.\lambda_{c} \frac{\partial T}{\partial z}\right|_{z=L_{m}+0}=\left.r_{k} \frac{K_{g}}{\mu_{g}} \frac{\partial P_{g}}{\partial z}\right|_{z=L_{m}+0}, \quad T=T_{m} .
$$

The boundary conditions at the boundary $z=L$ express the heat transfer between the surfaces of the plate and the drying agent according to Newton's

$$
\lambda_{c} \frac{\partial T}{\partial z}+\tilde{\alpha}\left(T-T_{\alpha}(\tau)\right)=0
$$

where $\tilde{\alpha}$ is the coefficient of heat exchange; $T_{\alpha}(\tau)$ is time-varying temperature of the drying agent. To model time-varying multi-stage drying schedules [16,24], the function $T_{\alpha}(\tau)$ can be represented as a polynomial in exponential functions

$$
T_{\alpha}=T_{1}+\left(T_{2}-T_{1}\right) \sum_{i=1}^{N}\left(\alpha_{i} e^{-b_{i} \tau}\right)=\alpha_{0}+\sum_{i=1}^{N}\left(\alpha_{i} e^{-b_{i} \tau}\right) .
$$

Here, for convenience, it is redesignated:

$$
\alpha_{0}=T_{1}, \quad \alpha_{i}=\left(T_{2}-T_{1}\right) a_{i}, \quad D^{\prime}=D_{i j}^{1}=\left(1 / D_{i}^{\infty}+\left(1-\alpha_{i j} z_{i}\right) / D_{i j}\right)^{-1},
$$

$D_{\nu \alpha}^{1}=D_{\alpha \nu}^{1}=D^{\prime}$ is effective diffusion coefficient; $D_{\nu \alpha}=D_{\alpha \nu}=D_{i j}$ is effective binary diffusion coefficient in macropores; the second term in the expression $D_{\nu}^{\infty}=D^{\infty}$ takes into account the effect 
of the Knudsen flow of vapor in the micropores. The parameters $\alpha_{i}, b_{i},(i=\overline{1, N})$ are determined by approximating a specific temperature regime of the drying agent. The parameter $N$ can specify a predetermined number of required steps of the drying agent regime parameters.

At the initial moment, the temperature of the plate satisfies the condition

$$
T(t=0)=f(z),
$$

where $f(z)$ are temperature functions of periods of constant and decreasing drying rates.

The speed of movement of the phase transition interface $\bar{z}_{m}=L_{m} / L$ is determined from the conditions of mass balance, where $\rho_{L}$ is the density of water

$$
\frac{d \bar{z}_{m}}{d \tau}=-\frac{j\left(\bar{z}_{m}\right)}{\Pi \rho_{L} L} .
$$

Equations (1)-(10) make up a nonlinear mathematical model that describes the process of convective drying of a capillary-porous body (plate) taking into account the moving boundary of phase transitions.

An analytical-numerical method has been developed for the implementation of a mathematical model for the non-stationary regime of a drying agent which varies according to the exponential law (7). To do this, we turn to the dimensionless coordinate system, using substitutions $\tau=\alpha_{T} t / L^{2}, \bar{z}=$ $z / L, \bar{z}_{m}=L_{m} / L$, where $\bar{z}_{m}$ is the dimensionless coordinate of the phase transition boundary.

The analytical solution to the model is presented in the form

$$
T=\chi_{0}+\sum_{i=1}^{N} \chi_{i} e^{-b_{i} \tau}+T^{*}
$$

where $T_{1}=\chi_{0}+\sum_{i=1}^{N} \chi_{i} e^{-b_{i} \tau}$ is a solution of the heat conduction equation that satisfies the boundary conditions of the problem but does not satisfy the initial condition. But $T^{*}$ is a solution to the problem of heat conduction which satisfies the initial condition and homogeneous boundary conditions. The dominant function of a mathematical model with homogeneous boundary conditions is constructed:

$$
G\left(\bar{z}, \overline{z_{m}}, \xi, \tau\right)=\sum_{n=1}^{\infty} 2 H_{T} \frac{\frac{\sin \mu_{n}\left(\bar{z}-\bar{z}_{m}\right)}{\mu_{n}}\left(\cos \mu_{n}(1-\xi)+H_{T} \frac{\sin \mu_{n}(1-\xi)}{\mu_{n}}\right) e^{-\mu_{n}^{2} \tau}}{\cos \mu_{n}\left(1-\bar{z}_{m}\right)\left(\left(\mu_{n}^{2}+H_{T}^{2}\right)\left(1-\bar{z}_{m}\right)+H_{T}\right)}
$$

where $\mu_{g}$ are the roots of the transcendental equation $\operatorname{tg} \mu_{g}\left(1-\bar{z}_{m}\right)=-\mu_{g} / H$. Using the boundary conditions, formulas were obtained to determine $\chi_{0}$ and $\chi_{i},(i=\overline{1, n})$.

To find $T^{*}\left(\bar{z}, \bar{z}_{m}, \tau\right)$ we use function [12], which satisfies the conditions $T_{m}\left(\bar{z}_{m}, \tau\right)=0, u(1, \tau)=0$.

If the initial temperature distribution is uniform, i.e. $T(\bar{z}, 0)=T_{0}$, then it is obtained

$$
T_{0}^{*}\left(\bar{z}, \bar{z}_{m}\right)=\sum_{n=1}^{\infty} \frac{\sin \mu_{n}\left(\bar{z}-\bar{z}_{m}\right)}{\mu_{n}} \frac{2 T_{0} H_{T}}{\Delta_{n}}\left(\frac{\sin \mu_{n}\left(1-\bar{z}_{m}\right)}{\mu_{n}}-\frac{H_{T}}{\mu_{n}^{2}}\left(\cos \mu_{n}\left(1-\bar{z}_{m}\right)-1\right)\right),
$$

The temperature during non-steady convective drying can be written

$$
T(\bar{z}, \tau)=\chi_{0}(\bar{z})+\sum_{i=1}^{N} \chi_{i}(\bar{z}) e^{-b_{i} \tau}+\sum_{n=1}^{\infty} \frac{\sin \mu_{n}\left(\bar{z}-\bar{z}_{m}\right)}{\mu_{n}} Z_{n}\left(\bar{z}_{m}\right) e^{-\mu^{2} n \tau},
$$

where

$$
\begin{gathered}
Z_{n}\left(\bar{z}_{m}\right)=\frac{2 T_{0} H_{T}}{\Delta_{n}}\left(\frac{\sin \mu_{n}\left(1-\bar{z}_{m}\right)}{\mu_{n}}-\frac{H_{T}}{\mu_{n}^{2}}\left(\cos \mu_{n}\left(1-\bar{z}_{m}\right)-1\right)\right)+\left(Z_{n 1}-Z_{n 2}\right) \\
Z_{n 1}=\sum_{i=1}^{N} C_{i}\left(-\frac{\cos \left(\sqrt{b_{i}}\left(1-\bar{z}_{m}\right)\right)}{2\left(\sqrt{b_{i}}-\mu_{n}\right)}-\frac{\cos \left(\sqrt{b_{i}}\left(1-\bar{z}_{m}\right)\right)}{2\left(\sqrt{b_{i}}+\mu_{n}\right)}+\frac{\cos \left(\mu_{n}\left(1-\bar{z}_{m}\right)\right)}{2\left(\sqrt{b_{i}}-\mu_{n}\right)}+\frac{\cos \left(\mu_{n}\left(1-\bar{z}_{m}\right)\right)}{2\left(\sqrt{b_{i}}+\mu_{n}\right)}\right)
\end{gathered}
$$




$$
Z_{n 2}=\sum_{i=1}^{N} \frac{C_{i} H_{T}}{\mu_{n}}\left(\frac{\sin \left(\sqrt{b_{i}}\left(1-\bar{z}_{m}\right)\right)}{2\left(\sqrt{b_{i}}-\mu_{n}\right)}-\frac{\sin \left(\sqrt{b_{i}}\left(1-\bar{z}_{m}\right)\right)}{2\left(\sqrt{b_{i}}+\mu_{n}\right)}-\frac{\sin \left(\mu_{n}\left(1-\bar{z}_{m}\right)\right)}{2\left(\sqrt{b_{i}}-\mu_{n}\right)}+\frac{\sin \left(\mu_{n}\left(1-\bar{z}_{m}\right)\right)}{2\left(\sqrt{b_{i}}+\mu_{n}\right)}\right) .
$$

In this case, $T^{*}=T_{0}^{*}+T_{\chi}^{*}$ satisfies the conditions $T^{*}\left(z_{m}, \bar{z}_{m}\right)=T^{*}\left(\bar{z}_{m}, 1\right)=0$. This formula allows calculating the temperature at an arbitrary point of the plate at an arbitrary point in the drying time, depending on the coordinate of the phase transition plane.

The ratio was found to determine the dimensionless vapor density, the vapor pressure at an arbitrary point $\bar{z}$ of the wood plate during the drying process $[17,20]$. An equation was obtained to determine change in relative moisture content over time and the equation of motion of the phase boundary of the dried and moist zones

$$
\frac{d \bar{z}_{m}^{*}}{d t}=\frac{j\left(\bar{z}_{m}^{*}\right)}{\Pi \rho_{L} L}=\frac{\beta \rho_{n}}{\Pi \rho_{L} L}\left(-\alpha_{1}+A_{1} \bar{z}_{m}^{*} \sqrt{A_{2}+A_{3} \bar{z}_{m}^{*}+A_{1}^{2} \bar{z}_{m}^{* 2}}\right) .
$$

The solution of equation (18) was obtained under the initial condition $\bar{z}_{m}^{*}=0$. In the process of convective drying, an important characteristic is the duration of drying. Based on the proposed approach, the time is determined at which relative saturation reaches a value $\bar{z}_{m}^{*}=0$. It can be represented by a formula

$$
2 H_{m} A_{1} \tau=\ln \left|\frac{2 A_{1} \phi-A_{3}}{2 A_{1} \sqrt{A_{2}}-A_{3}}\right|+\frac{1}{2}\left(A_{3}^{2}-4 A_{1}^{2} A_{2}\right)\left(\frac{1}{\left(2 A_{1} \phi-A_{3}\right)^{2}}-\frac{1}{\left(2 A_{1} \sqrt{\phi} A_{2}-A_{3}\right)^{2}}\right) .
$$

A formula was also obtained to determine the complete drying time of a wood plate, taking into account the moving boundary of the phase transition $[20,25]$.

\section{Mathematical modeling of the effect of thermodiffusion on the moisture-mass trans- fer during drying of capillary-porous materials, taking into account the phase tran- sition boundary}

Mathematical modeling of the effect of thermal diffusion on the mass transfer of moisture during drying of wood plate was carried out. The mathematical model for studying mass transfer in the dried zone of a plate with allowance for diffusion, convective, heat fluxes is described by a system of differential equations:

$$
\begin{gathered}
\rho_{\nu} \frac{K}{\mu_{g}} \frac{\partial^{2} P}{\partial z}\left(\left(D+1.064 \sqrt{R T / M_{\nu}} \varepsilon\right)\left(\frac{\partial \rho_{\nu}}{\partial z}+\delta \frac{\partial T}{\partial z}\right)\right)=0, \\
\rho_{\alpha} \frac{K}{\mu_{g}} \frac{\partial^{2} P}{\partial z^{2}}+D \frac{\partial^{2} \rho_{\alpha}}{\partial z^{2}}=0,
\end{gathered}
$$

where $\varepsilon$ is the coefficient of molecular flow of vapor. Here we assume that the density of air is related to temperature directly due to the density of vapor.

The boundary conditions are as follows:

$$
\begin{aligned}
& \rho_{\nu} \frac{K}{\mu_{g}} \frac{\partial P}{\partial z}+\left(D+1.064 \varepsilon \sqrt{R T / M_{\nu}}\right) \cdot\left(\frac{\partial \rho_{\nu}}{\partial z}+\delta \frac{\partial T}{\partial z}\right)=-j, \\
& \rho_{\alpha}=\rho_{\alpha 0}, \quad z=L, \quad \rho_{\nu}=\rho_{n}, \quad j=\beta\left(\rho_{\nu}-\rho_{0}\right), \quad z=L_{m},
\end{aligned}
$$

where $\beta$ is the mass transfer coefficient, $\rho_{n}$ is the density of saturated vapor at a given temperature, $\rho_{0}$ is the vapor density in the environment outside the plate, $\rho_{\alpha 0}$ is the air density on the outer surfaces of the plate. 
A relation is established to determine the vapor density and pressure at an arbitrary point of the plate

$$
\begin{gathered}
\bar{\rho}_{\nu}=-A+\sqrt{A_{2}-2 A_{1}\left(\bar{\rho}_{\nu 1}-\bar{\rho}_{\nu 0}\right)\left(\bar{z}-\bar{z}_{m}\right)-2 A \delta^{\prime}\left(T-T_{m}\right)} \\
P\left(\bar{z}, \bar{z}_{m}\right)=\left(-A+\sqrt{A_{2}-2 A_{1}\left(\bar{\rho}_{\nu 1}-\bar{\rho}_{\nu 0}\right)\left(\bar{z}-\bar{z}_{m}\right)-2 A \delta^{\prime}\left(T\left(\bar{z}, \bar{z}_{m}\right)-T_{m}\right)}\right) \frac{\rho_{n}}{M_{\nu}} R T\left(\bar{z}, \bar{z}_{m}\right) .
\end{gathered}
$$

Further, using (23), (24) and linearized boundary conditions (22) on the surface $\bar{z}=1$. The flow density $\mathrm{j}$ and the mass of moisture lost during the drying of the plate were determined. The established dependences made it possible to obtain an equation for determining the change in relative moisture content over time and the equation of motion of the phase boundary in the drying process of the wood plate under

$$
\frac{d \bar{z}_{m}^{*}}{d \tau}=\frac{j\left(\bar{z}_{m}^{*}\right)}{\Pi \rho_{L} L}=\frac{\beta \bar{z}_{m}^{*}}{\Pi \rho_{L} L}\left(-\left(\alpha_{1}+B \bar{z}_{m}^{*}\right)+\sqrt{A_{2}+A_{3} \bar{z}_{m}^{*}+A_{1}^{2} \bar{z}_{m}^{*}-2 A \delta^{\prime}\left(T_{1}-T_{m}\right)}\right) .
$$

A dependence is established for determining the time at which the relative saturation in the plate being dried reaches a value $\bar{z}_{m}^{*}$ provided $\partial\left(T_{1}-T_{m}\right) / \partial \bar{z}_{m}^{*} \ll 1$, but taking into account the thermal gradient component

$$
\begin{aligned}
2 H_{1} A_{1} \tau=\ln \left|\frac{2 A_{1} \phi-\left(A+\rho_{0}\right)}{2 A_{1} \sqrt{A_{2}}-A_{3}}\right|+\frac{1}{2}\left(A_{3}^{2}-4 A_{1}^{2}\left(A_{2}-\right.\right. & \left.\left.2 A \delta^{\prime}\left(T_{1}-T_{m}\right)_{z_{n}=1}\right)\right) \\
& \times\left(\frac{1}{\left(2 A_{1} \phi-A_{3}\right)^{2}}-\frac{1}{\left(2 A_{1} A_{2} \sqrt{\phi}-A_{3}\right)^{2}}\right) .
\end{aligned}
$$

Also, a formula is obtained for determining the total drying time of wood taking into account the change of the moving boundaries of the phase transition. An analytical dependence is found to determine the phase transition temperature taking into account the temperature gradient over the plate thickness,

$$
\begin{aligned}
\left(H_{T} \sqrt{A_{2}} x_{1}+x_{2}\right) T_{m}^{2}+\left(x_{1}\left(1+H_{T} \Psi\right) \sqrt{A_{2}}\right. & \left.-x_{2} T_{m k} / \alpha_{m k}+r_{k} K_{g} T_{m k} H_{T} \sqrt{A_{2}}\right) T_{m} \\
& +r_{k} K_{g} T_{m k} \Psi\left(\bar{z}_{m}, \tau\right) \sqrt{A_{2}}\left(1+H_{T}\left(1-\bar{z}_{m}\right)\right)=0 .
\end{aligned}
$$

The notation is introduced here:

$$
\begin{gathered}
-\lambda_{c} \mu_{g} \alpha_{m k}+r_{k} K_{g}=x_{1} ; \\
r_{k} K_{g}\left(A_{1}\left(\bar{\rho}_{\nu 1}-\bar{\rho}_{\nu 0}\right)\left(1+H_{T}\left(1-\bar{z}_{m}\right)\right) \alpha_{m k}\right)=x_{2} ; \\
-r_{k} K_{g} T_{m k} H_{T} \sqrt{A_{2}}=x_{3} .
\end{gathered}
$$

The coefficients of the equation obtained are functions of the coordinate of the phase transition, the specific temperature of vaporization, the coefficients of heat and mass transfer, the conductivity and dynamic viscosity of the gas, the parameters of the drying schedule, the relative moisture saturation of the surface layer and the drying agent and the temperature gradient, average carcass temperature. If we neglect the influence of the phase transition gradient in this formula, then we obtain the following dependence of the phase transition temperature

$$
T_{m}=\frac{r_{k} K_{g} T_{m k}\left(A_{1}\left(\bar{\rho}_{\nu 1}-\bar{\rho}_{\nu 0}\right)\left(1+H_{T}\left(1-\bar{z}_{m}\right)\right)-H_{T} \sqrt{A_{2}}\right)}{H_{T} \sqrt{A_{2}}\left(-\lambda_{c} \mu_{g} \alpha_{m k}+r_{k} K_{g}\right)+r_{k} K_{g}\left(A_{1}\left(\bar{\rho}_{\nu 1}-\bar{\rho}_{\nu 0}\right)\left(1+H_{T}\left(1-\bar{z}_{m}\right)\right) \alpha_{m k}\right)} .
$$

From this formula it follows that the phase transition temperature is a nonlinear function of the coefficients of heat exchange and mass transfer of the material, the temperature of the drying agent, the specific heat of vaporization, the location of the phase transition coordinate. 


\section{Mathematical modeling of heat transfer during drying of anisotropic capillary-porous materials taking into account the phase transition boundary}

A two-dimensional mathematical model of the process of convective drying of anisotropic porous materials is constructed taking into account the motion of the phase transition boundary. Determined is the influence of the main components and the orientation of the main axes of the heat transfer tensor on unsteady temperature fields in a prismatic bar of rectangular cross-section $\left\{2 L_{1}, 2 L_{2}\right\}$ taking into account the motion of the boundaries of phase transitions. An analytical-numerical method is developed and algorithms for the implementation of a nonlinear mathematical model under variable temperature conditions of the environment are constructed. We believe that the drying conditions along the length of the bar are the same. Therefore, we consider the problem of heat distribution and the formation of a dried zone in its cross-section, the external contour of which in variables $x_{1}, x_{2}$ is described by the equation

$$
F_{0}=\left(x_{1}^{2}-L_{1}^{2}\right)\left(x_{2}^{2}-L_{2}^{2}\right) .
$$

In the process of heat exchange of the body with the drying agent, a dried zone is formed, extending from the outer surface to the depth of the body. Let the dried and damp zone be separated by a cylindrical surface, whose generators are parallel to the axis of the bar, and the closed contour of its cross-section is their guide line. Its equation takes the form:

$$
F_{m}=F_{0}-\varepsilon(\tau),
$$

where $\varepsilon(\tau)$ is an unknown function of time.

The temperature of the porous prismatic orthotropic body in the dried zone is described by the equation:

$$
\begin{aligned}
\left(\Pi\left(C_{\nu} \rho_{\nu}+C_{\alpha} \rho_{\alpha}\right)+(1-\Pi) C_{s} \rho_{s}\right) \frac{\partial T}{\partial \tau} & =\frac{\partial}{\partial x_{1}}\left(\lambda_{11} \frac{\partial T}{\partial x_{1}}\right) \\
& +\frac{\partial}{\partial x_{2}}\left(\lambda_{22} \frac{\partial T}{\partial x_{2}}\right)+\left(\lambda_{12}+\lambda_{21}\right) \frac{\partial^{2} T}{\partial x_{1} \partial x_{2}}+F\left(x_{1}, x_{2}, \tau\right)
\end{aligned}
$$

Here, the indices $\nu, \alpha, s$ denote the components of vapor, air, carcass, and $\Pi, C_{\nu}, C_{\alpha}, C_{s}, \rho_{\nu}, \rho_{\alpha}, \rho_{s}$ denote porosity, heat capacity, vapor density, air, carcass, respectively; $\lambda_{i j}$ are components of the heat conduction tensor; $T$ is temperature. On the surface of the body, there are boundary conditions of the third kind.

The main coefficients of heat conduction are determined through the coefficients of heat conduction of the orthotropic material

$$
\begin{gathered}
x_{1}=\lambda_{12} x_{1}^{\prime} / \Delta^{\prime}+\sqrt{\lambda_{22}-\lambda_{2}} \cdot x_{2}^{\prime} / \Delta^{\prime \prime} ; \quad x_{2}=\left(\lambda_{11}-\lambda_{1}\right) \cdot x_{1}^{\prime} / \Delta^{\prime}+\lambda_{21} x_{2}^{\prime} / \Delta^{\prime \prime} ; \\
\Delta^{\prime}=\sqrt{\left(\lambda_{11}-\lambda_{1}\right)^{2}+\lambda_{12}^{2}} ; \quad \Delta^{\prime \prime}=\sqrt{\left(\lambda_{22}-\lambda_{2}\right)^{2}+\lambda_{21}^{2}} .
\end{gathered}
$$

The variables $\left(x_{1}^{\prime}, x_{2}^{\prime}\right)$ coincide with the main directions of anisotropy of the heat conduction of the plate. If we pass on to the variables $\xi_{1}=\left(\lambda / \lambda_{1}\right)^{1 / 2} x_{1}^{\prime}, \xi_{2}=\left(\lambda / \lambda_{2}\right)^{1 / 2} x_{2}^{\prime}$, then in the drying zone we use the equation

$$
\frac{\partial T}{\partial \tau^{*}}=\left(\frac{\partial^{2} T}{\partial \xi_{1}^{2}}+\frac{\partial^{2} T}{\partial \xi_{2}^{2}}\right)
$$

It is important to obtain boundary conditions on the surfaces of an orthotropic prism in variables $\xi_{1}, \xi_{2}$ :

$$
\frac{\partial T}{\partial \xi_{i}} \pm H_{i} \cdot(T-u(t))=0
$$

where $H_{i}^{*}=\sqrt{\lambda_{i} / \lambda} \frac{l_{1}}{m_{1} l_{2}+m_{2} l_{1}} H_{i}, H_{i}=\tilde{\alpha_{i}} / \lambda_{i}, \tilde{\alpha}_{i}$ are heat exchange coefficients.

Mathematical Modeling and Computing, Vol. 8, No. 4, pp. 830-841 (2021) 
The contour of the cross-section of the bar in the variables $\xi_{1}, \xi_{2}$ is described by the equation

$$
F_{0}\left(\xi_{1}, \xi_{2}\right)=\left(\xi_{1}^{2}-\Delta_{1}^{2}\right)\left(\xi_{1}^{2}-\Delta_{2}^{2}\right)\left(\xi_{2}^{2}-\Delta_{3}^{2}\right)\left(\xi_{2}^{2}-\Delta_{4}^{2}\right)=0 .
$$

From this surface, the drying process moves inside the body. Given that the volume of the dried area of the bar is a function of time, we present the equation of the boundary of the dried and moist areas in the form:

$$
F_{m}\left(\xi_{1}, \xi_{2}, \tau\right)=\left(\xi_{1}^{2}-\Delta_{1}^{2}\right)\left(\xi_{1}^{2}-\Delta_{2}^{2}\right)\left(\xi_{2}^{2}-\Delta_{3}^{2}\right)\left(\xi_{2}^{2}-\Delta_{4}^{2}\right)-\delta \varepsilon(\tau)=0 .
$$

We introduce the following values: $\left(T\left(\xi_{1}, \xi_{2}, \tau\right)-T_{m}\right) /\left(T_{\Pi}-T_{m}\right)=\eta, \beta=\rho_{m} c_{m} \bar{\alpha} / \lambda_{m}=\bar{\alpha} / \bar{\alpha}_{m}$, $\tau^{*}=\tau \bar{\alpha}$, where $T_{\Pi}, T_{m}$ is the temperature at the cross-section contour of the bar and at the boundary of the phase transition. From the condition of continuity of the heat flux between surfaces $F_{0}$ and $F_{m}$, we find the value of $\eta$ :

$$
\eta=\left(\left(\xi_{1}^{2}-\Delta_{1}^{2}\right)\left(\xi_{1}^{2}-\Delta_{2}^{2}\right)\left(\xi_{2}^{2}-\Delta_{3}^{2}\right)\left(\xi_{2}^{2}-\Delta_{4}^{2}\right)-\delta \varepsilon(\tau)\right) /(-\delta \varepsilon(\tau)), \quad \delta=\Delta_{1}^{2} \Delta_{2}^{2} \Delta_{3}^{2} \Delta_{4}^{2} .
$$

The equation of the phase transition curve in the cross-section of the bar is explicitly defined:

$$
\xi_{2}= \pm \sqrt{\delta_{3} \pm \sqrt{\delta_{4}^{2}+\frac{\delta \varepsilon(\tau)}{\left(\xi_{1}^{2}-\Delta_{1}^{2}\right)\left(\xi_{1}^{2}-\Delta_{2}^{2}\right)}}}
$$

To devise an analytical-numerical method for implementing the mathematical model, the heat balance equation [1,2] is adapted, taking into account the moving boundary of the phase transition, in the region limited by the outer contour of the cross section of the bar and the contour of the phase transition boundary:

$$
\iint_{F_{m}}^{F_{0}=0} \frac{d \eta}{d \tau^{*}} d s=\oint_{F_{0}} \frac{\partial \eta}{\partial n} d l+\beta \eta \frac{\partial V}{\partial \tau^{*}}, \quad V\left(F_{m}, F_{0}\right)=\iint_{F_{m}=0}^{F_{0}=0} d s=\iint_{S_{\Pi}} d s-\iint_{S_{\Phi}} d s .
$$

In order to calculate the integrals included in formula (38), the equation of the line of the phase transition contour is explicitly obtained, as well as the boundaries of the corresponding integrals are established. The double integrals in (38) on the surface between the closed contour $F_{m}$ and the outer contour $F_{0}$ will be found as the difference between the integral over the surface of the entire cross-section and the integral over the surface $S_{\Phi}$, bounded by the contour $F_{m}$.

The volume of the dried zone, referred to the unit length of the bar, which is located between the planes $F_{0}=0, F_{m}=0$, is determined by the formulas:

$$
\begin{aligned}
V\left(F_{0}, F_{m}\right)= & \iint_{F_{m}=0}^{F_{0}=0} d x_{1} d x_{2}=4 L_{1} L_{2}-4 \sqrt{\lambda_{1} / \lambda} \sqrt{\lambda_{2} / \lambda} \int_{0}^{\gamma}\left(\left(\delta_{3} \sqrt{\left(\xi_{1}^{2}-\Delta_{1}^{2}\right)\left(\xi_{1}^{2}-\Delta_{2}^{2}\right)}\right.\right. \\
& \left.\left.-\sqrt{\delta_{4}^{2}\left(\xi_{1}^{2}-\Delta_{1}^{2}\right)\left(\xi_{1}^{2}-\Delta_{2}^{2}\right)+\delta \varepsilon}\right)^{1 / 2} /\left(\left(\xi_{1}^{2}-\Delta_{1}^{2}\right)\left(\xi_{1}^{2}-\Delta_{2}^{2}\right)\right)^{1 / 4}\right) d \xi_{1} .
\end{aligned}
$$

We determine the derivative of volume by time, taking into account the time dependence of the value $\varepsilon\left(\tau^{*}\right)$ and the time dependence of the upper boundary of the integral:

$$
\frac{\partial V}{\partial \tau^{*}}=\sqrt{\lambda_{1} / \lambda} \sqrt{\lambda_{2} / \lambda} \frac{d \varepsilon}{d \tau}\left(J_{V}+J(\varepsilon)+A(\varepsilon)\right)
$$

where $A=f\left(\gamma\left(\tau^{*}\right), \tau^{*}\right) \frac{d \gamma\left(\tau^{*}\right)}{d \tau^{*}}$ is functional dependence, $J_{V}, J(\varepsilon)$ are integrals. Here, the functions of time is the integration limit:

$$
\begin{gathered}
\gamma=\sqrt{\delta_{1}^{2}+\sqrt{\delta_{2}^{2}+\varepsilon \Delta_{1}^{2} \Delta_{2}^{2}}}, \\
\tau^{*}=1 / 2 \sqrt{\delta_{1}^{2}+\sqrt{\delta_{2}^{2}+\varepsilon \Delta_{1}^{2} \Delta_{2}^{2}}} \Delta_{1}^{2} \Delta_{2}^{2} / 2 \sqrt{\delta_{2}^{2}+\varepsilon \Delta_{1}^{2} \Delta_{2}^{2}} \frac{d \varepsilon}{d \tau^{*}} .
\end{gathered}
$$

Mathematical Modeling and Computing, Vol. 8, No. 4, pp. 830-841 (2021) 
The proposed approach based on the heat balance equation (38) with phase transition and dependences (39)-(41) made it possible to obtain an equation for determining the phase transition boundary in an orthotropic bar during drying in the form:

$$
\frac{\partial \varepsilon}{\partial \tau^{*}} I\left|J_{S_{\Phi}}-J_{\Phi}\right|=\varepsilon\left(c_{1} J_{\gamma_{1}}+c_{2} J_{\gamma_{2}}\right)+\varepsilon^{2} I \beta \eta\left(J_{V}-A\right) .
$$

The integrals $J_{\Phi}(\varepsilon), A(\varepsilon), J_{V}(\varepsilon)$ along the boundary of the phase transition are determined by the numerical method [18]. The integrals $J_{\gamma_{1}}$ and $J_{\gamma_{2}}$ are calculated on the boundary of a given area in the coordinate system $\left(\xi_{1}, \xi_{2}\right)$. All other values included in this equation are calculated using the physical and thermal characteristics of a particular wood material and operating parameters of drying.

Formulas are obtained for determining the temperature at an arbitrary point of a wood bar at an arbitrary instant of drying, depending on the coordinate of the phase transition plane, changes in temperature and humidity of the drying agent.

\section{Simulation results}

Application of the developed mathematical models and applied programmatic facilities is shown for the research of processes of heat-mass transfer of wood during drying. For numeral experiments some thermo-physical descriptions of wood are specified. Especially, on the basis of working of experimental data dependence of coefficient of wood hydraulic conductivity as functions from a temperature and humidity is used $[1,19]$. On the basis of mathematical models, the dependences of the temperature change during the drying process (Fig. 1) on different values of nondimensional time $F_{0}$ and changes in the evaporation boundary are analyzed (Fig. 2$)$ in the wood plate $\left(\rho_{0}=460 \mathrm{~kg} / \mathrm{m}^{3}\right)$ on various values of temperature and moisture content of convective drying agent. Fig. 2 characterizes the change in the boundary of the evaporation zone in the wood plate during the drying process for different values of the temperature of the drying agent. Curve 1 corresponds to $t_{c}=50^{\circ} \mathrm{C}$, curve $2-t_{c}=60^{\circ} \mathrm{C}$, curve $3-t_{c}=70^{\circ} \mathrm{C}$, curve $4-t_{c}=80^{\circ} \mathrm{C}$, curve $5-t_{c}=90^{\circ} \mathrm{C}$. Fig. 3 describes the distribution of the relative concentration of the vapor pressure $P / P_{0}$ for different values of the drying process at cross-section points when changing the coordinates of the phase transition boundary are shown in Fig. 4. The obtained numerical results indicate that the effect of the temperature component $T^{*}(\bar{z}, \tau)$ under mild schedule of wood drying (when the temperature of the drying agent varies from $20^{\circ} \mathrm{C}$ to $40^{\circ} \mathrm{C}$ is relatively small, and the intensity of phase transitions depends on the difference of pressure in the pores and in the drying agent (Fig. 4).

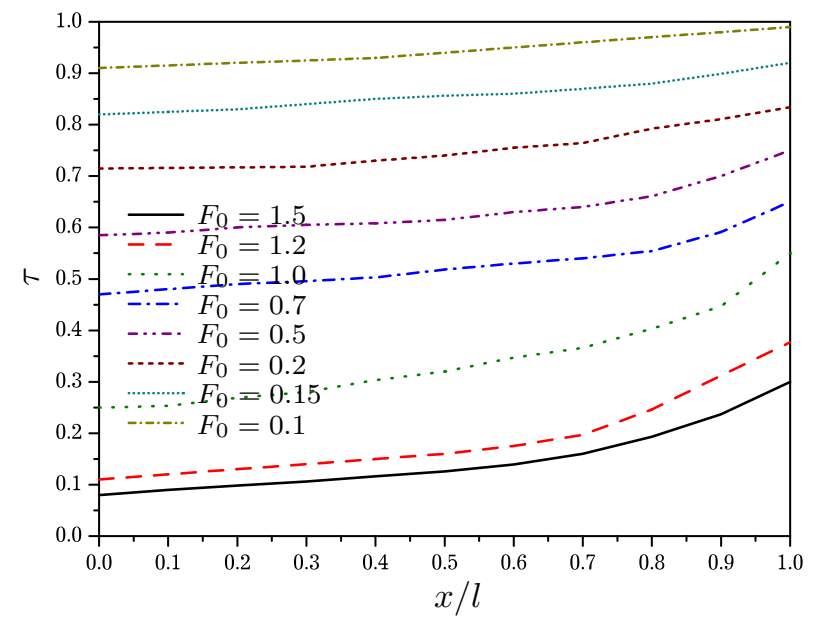

Fig. 1. The change in relative temperature during the drying of the wood plate depending on the nondimensional time $F_{0}$.

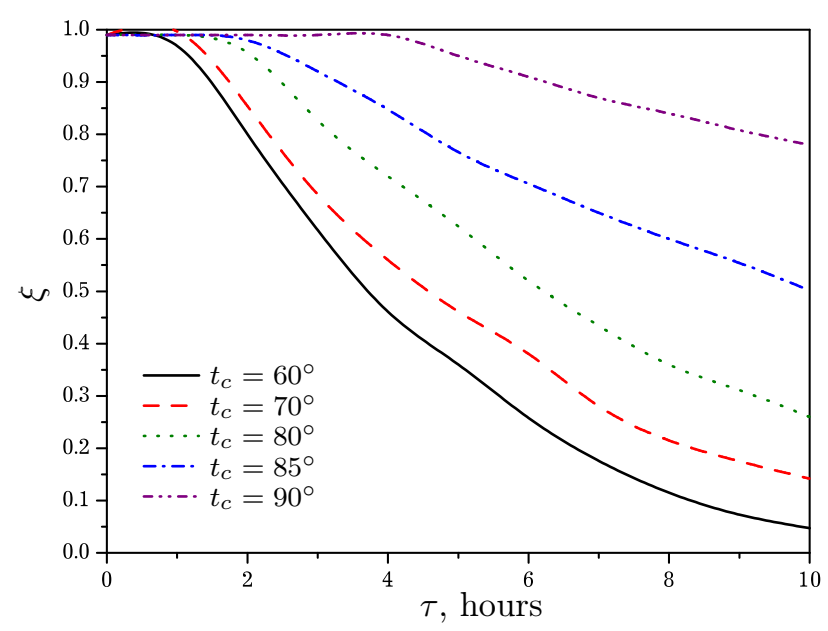

Fig. 2. Changing the evaporation boundary in a wood plate during drying for different values of the ambient temperature $t_{c}$. 


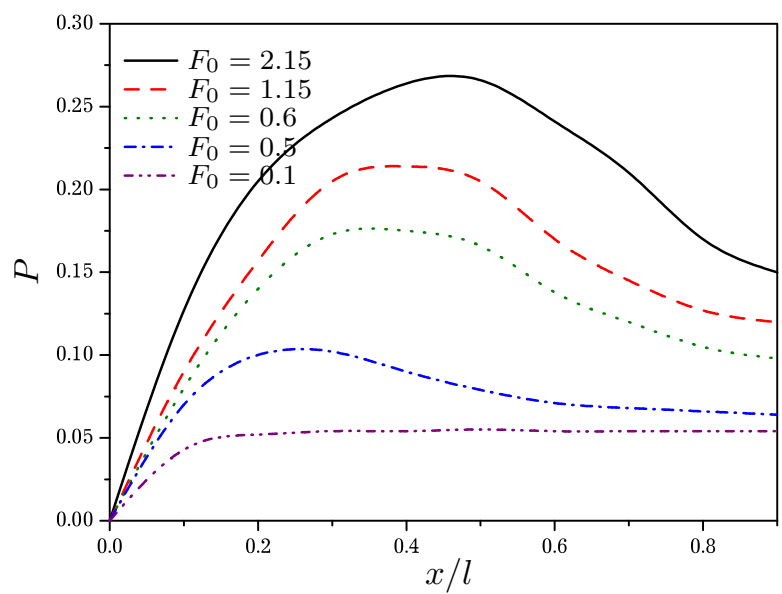

Fig. 3. Change in vapor pressure during the drying of the wood plate for different values of drying time.

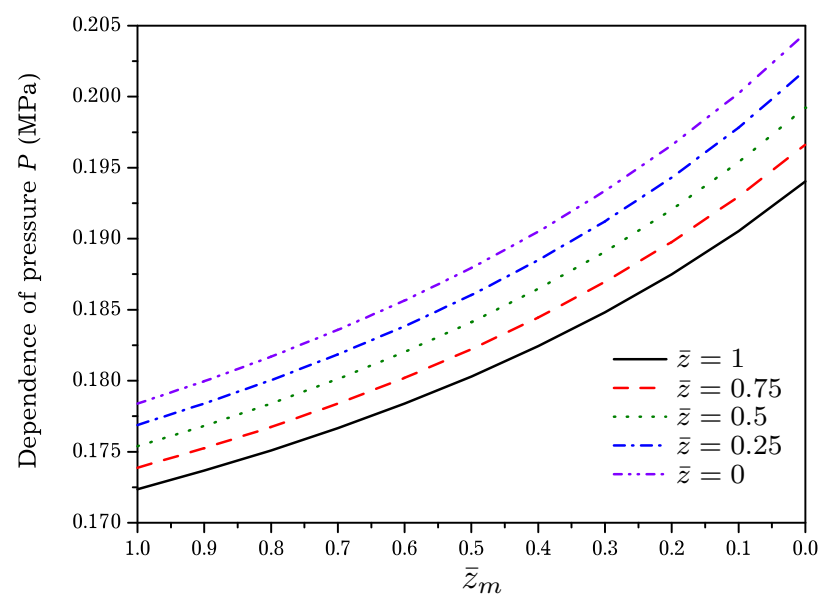

Fig. 4. Dependence of pressure $P\left(\bar{z}, \bar{z}_{m}\right)$ at points of cross-section of a plate when changing the coordinates of the phase transition boundary.

An analysis of the graphical dependencies indicates that during the drying process of wood $\left(\rho_{0}=\right.$ $460 \mathrm{~kg} / \mathrm{m}^{3}$ ) with an initial moisture content $U_{0}=0.6 \mathrm{~kg} / \mathrm{kg}$ for the first period, intensive heating is carried out, which leads to rapid vaporization. The temperature of the surface layers of wood throughout the entire period is higher than in the middle layers. In the hottest layers of wood, by the end of the first period of the drying process, their is a maximum residual pressure. This pressure occurs for a material temperature that is lower than the saturation temperature for a given atmospheric pressure. The second period of the drying process is characterized by a relative stabilization of the growth of the temperature field. This is due to the absorption of a significant amount of heat in the process of internal vaporization, which in turn causes a rapid increase in residual internal pressure. The presence of such a pressure gradient directed into the inner layers of the wood intensifies the process of moisture release. At the beginning of the period of constant drying rate, a combination of the fronts of the maximum values of the internal residual pressure is observed. In the middle of this period, its values reach their maximum magnitude, and after that their gradual decrease is observed. An analysis of the temperature fields for the period of decreasing drying rate shows their growth in the entire volume of the material until the temperature of the central layer is equal to the temperature of the surface layers. Since this period is characterized by the release of bound moisture, the duration of this period is quite long. However, the intensity of internal pressure drop is higher than in previous periods.

\section{Conclusions}

A nonlinear mathematical model of non-isothermal moisture transfer during drying of capillary-porous materials is constructed, taking into account the moving boundaries of the moisture evaporation zone. Analytical dependences are obtained for determining the temperature, moisture content, vapor density, vapor pressure in the wood plate at an arbitrary time of drying depending on the coordinate of the phase transition, thermophysical characteristics of the material and the parameters of the drying agent.

An equation is obtained to determine the moving boundary between the dried and moist zones of the wood plate. Calculation relationships are established to determine the phase transition temperature, taking into account the transport gradients and the time for which the relative saturation reaches the boundaries of the phase transition. The coefficients of the obtained equation are functions of the phase transition coordinate, specific vaporization temperature, heat-and-mass transfer coefficients, coefficients of conductivity and dynamic gas viscosity, the parameters of drying schedule, relative saturation of the moist surface of the layer and drying medium and temperature gradient, average 
material temperature. The dependences are established for determining the total drying time, taking into account the moving boundary of the phase transition.

A two-dimensional mathematical model of heat transfer is formulated for non-stationary schedules of convective drying of anisotropic capillary porous materials, taking into account the moving boundaries of the evaporation zone. The heat balance equation is adapted, taking into account the moving boundary of the phase transition. This made it possible to develop an analytical-numerical method for calculating heat transfer in an orthotropic plate with a moving boundary of phase transitions and to obtain an equation for determining the moving boundaries of a phase transition depending on the orthotropic thermophysical characteristics of the material, temperature and relative humidity of the drying agent.

Investigated was the influence of thermal diffusion, initial values of temperature and moisture content, thermophysical characteristics of the material and schedule parameters of the drying agent on the temperature of phase transitions. The patterns of diffusion and convective heat-and-mass transfer for different periods of the drying process, depending on the zone of moisture evaporation, have been established.

[1] John F. Sian. Wood: influence of moisture on physical properties. Virginia (2004).

[2] Lykov A. V. Heat and mass transfer: a reference. Energy, Moscow (1971), (in Russian).

[3] Grinchik N. N., Adamovich A. L., Kizina O. A., Kharma U. M. Modeling of heat and moisture transfer in wood in finish drying by the energy of a microwave field. Journal of Engineering Physics and Thermophysics. 88, 35-41 (2015).

[4] Igoshin D. E. Model of drying a thin layer of moisture-porous medium. Bulletin of Tyumen State University. 7, 20-28 (2013).

[5] Chemkhi S., Zagrouba F., Bellagi A. Modelling and simulation of drying phenomena with rheological behavior. Brazilian Journal of Chemical Engineering. 22 (2), 153-163 (2005).

[6] Arutunyan R. V. Modeling of stochastic filtration processes in lattice systems. Mathematical Modeling and Numerical Methods. 16, 17-30 (2017).

[7] De la Cruz-Lefevre R., Remond R., Aleon D., Perre P. Effect of oscillating drying conditions on variations in the moisture content field inside wood boards. Wood Material Science and Engineering. 5, 84-90 (2019).

[8] Kartashov E. M. Heat conduction at a variable heat-transfer coefficient. High Temperature. 57 (5), 663670 (2019).

[9] Kostrobij P. P., Markovych B. M., Tokarchuk M. V. Generalized diffusion equation with nonlocality of space-time. Memory function modelling. Condensed Matter Physics. 23 (2), 23003 (2020).

[10] Gupta S. C. The Classical Stefan Problem. 2nd edition. Elsevier, USA (2017).

[11] Vasilyev V. I., Vasilyev M. V., Stepanov S. P., et al. Mathematical modeling of the temperature regime of soil of foundations in conditions of perennially frozen rocks. The Natural Science series. 1 (70), 142-159 (2017).

[12] Skopetskyi V. V., Bulavatskyi V. M., Kryvonos U. G. Nonclassical mathematical models of heat and mass transfer processes. Scientific thought (2005).

[13] Oztop F. H., Akpinar E. K. Numerical and experimental analysis of moisture transfer for convective drying of some products. International Communications in Heat and Mass Transfer. 35 (2), 169-177 (2008).

[14] Li X., Thomas H. R. Finite element method and constitutive modeling and computation for unsaturated soils. Computer Methods in Applied Mechanics and Engineering. 169 (1-2), 135-159 (1999).

[15] Krylov D. A., Sydnev N. I., Fedotov A. A. Mathematical modeling of the distribution of temperature fields. Mathematical modeling. 25 (7), 3-27 (2013).

[16] Sokolovskyy Ya., Boretska I., Yatsyshyn S., Kaspryshyn Y. Mathematical modeling of deformationrelaxation processes under phase transition. CEUR Workshop Proceedings. 2300, 83-86 (2018).

[17] Sokolovskyy Y., Boretska I., Kroshnyy I., Gayvas B. Mathematical models and analysis of the heat-masstransfer in anisotropic materials taking into account the boundaries of phase transition. 15th International Conference "The Experience of Designing and Application of CAD Systems". 28-33 (2019). 
[18] Samarskii A. A. The theory of difference schemes. Science, Moscow (1989), (in Russian).

[19] Shymanskyi V., Protsyk Y. Simulation of the heat conduction process in the claydite-block construction with taking into account the fractal structure of the material. Proceedings of the 2018 IEEE XIII-th International Scientific and Technical Conference "Computer Sciences and Information Technologies". 151154 (2018).

[20] Sokolovskyy Ya., Boretska I., Gayvas B., Kroshnyy I. Mathematical modeling of the heat-mass-exchange in anisotropic environments taking into account the boundary of phase transition. Proceedings of the 2018 IEEE XIII-th International Scientific and Technical Conference "Computer Sciences and Information Technologies". 147-150 (2018).

[21] Kostrobij P., Markovych B., Viznovych B., Zelinska I., Tokarchuk M. Generalized Cattaneo-Maxwell diffusion equation with fractional derivatives. Dispersion relations. Mathematical Modeling and Computing. 6 (1), 58-68 (2019).

[22] Kostrobij P. P., Markovych B. M., Ryzha I. A., Tokarchuk M. V. Generalized kinetic equation with spatiotemporal nonlocality. Mathematical Modeling and Computing. 6 (2), 289-296 (2019).

[23] Sokolovskyy Y., Kroshnyy I., Yarkun V. Mathematical modeling of visco-elastic-plastic deformation in capillary-porous materials in the drying process. The X-th International Conference on Computer Science and Information Technologies. 52-56 (2015).

[24] Sokolovskyy Y., Sinkevych O. Software for automatic calculation and construction of chamber drying wood and its components. The XII International Conference "Perspective Technologies and Methods in MEMS Design". 209-213 (2016).

[25] Sokolovskyy Y., Boretska I., Gayvas B., Shymanskyi V., Gregus M. Mathematical modeling of heat transfer in anisotropic biophysical materials, taking into account the phase transition boundary. CEUR Workshop Proceedings. 2488, 121-132 (2019).

[26] Sokolovskyy Y., Levkovych M., Sokolovskyy I. The study of heat transfer and stress-strain state of a material, taking into account its fractal structure. Mathematical Modeling and Computing. 7 (2), 400-409 (2020).

\title{
Математичне моделювання конвективного процесу сушіння деревини з урахуванням границі фазових переходів
}

\author{
Соколовський Я. I. ${ }^{1}$, Борецька I. Б. ${ }^{2}$, Гайвась Б. I. ${ }^{3}$, Крошний I. M. ${ }^{2}$, Нечепуренко А. В. ${ }^{2}$ \\ ${ }^{1}$ Начіональний університет "Львівсъка політехніка", \\ вул. С. Бандери, 12, 79013, Львів, Україна \\ ${ }^{2}$ Національний лісотехнічний університет України, \\ вул. Г. Чупринки, 103, 79057, Львів, Україна \\ ${ }^{3}$ Інститут прикладних проблем механіки $і$ математики ім. Я. С. Підстригача НАН Украӥни, \\ вул. Наукова, ЗБ, 79060, Лъвів, Україна
}

\begin{abstract}
У роботі розглядається побудова та впровадження математичних моделей неізотермічного вологоперенесення під час сушінні анізотропних капілярно-пористих матеріалів, зокрема деревини, з врахуванням руху зони випаровування для нестаціонарних режимів сушіння, а також розроблення ефективних аналітичних та числових методів їх реалізації. Розроблено аналітико-числовий метод визначення неізотермічного вологоперенесення для нестаціонарних режимів процесу сушіння з урахуванням динаміки зміни границі фазового переходу. Встановлено розрахункові співвідношення для визначення температури фазового переходу з урахуванням градієнтів перенесення та часу, для якого відносна насиченість досягає границь фазового переходу.
\end{abstract}

Ключові слова: граниия фазового переходу, неізотермічне вологоперенесення, математична модель. 